\title{
KEY PROCESSES FOR THE CONSTRUCTION OF AN INFORMAL GUIDE TO DEVELOP DIGITAL COMPETENCES: SUPPORT RESETTLED REFUGEES IN ACTIVE JOB SEARCH
}

\author{
A. Trindade ${ }^{1}$, G. Miranda ${ }^{2}$, A. Balula ${ }^{3}$ \\ ${ }^{1}$ Universidade de Aveiro (PORTUGAL) \\ 2Universidade de Lisboa, Instituto de Educação (PORTUGAL) \\ ${ }^{3}$ ESTGA - Universidade de Aveiro, CIDTFF (Portugal) (PORTUGAL)
}

\begin{abstract}
Any kind of learning program requires a set of processes to make sure that learning can happen in a specific environment. This means that it is important to identify the method and instructional model that can help learners getting engaged in a specific theme, in this case in developing digital competences.

In this work, we present the method followed to build an informal Guide for refugees to develop digital competences, to support their active job search (which is part of an ongoing Ph.D. project). Hence, the five processes of Cognitive Theory of Multimedia Learning were used (i.e. selecting words; selecting images; organizing images; organizing words; integrating) to present text, graphics, video and audio information for optimal learning.

For the creation of this informal Guide, an analysis model was developed to support the research process, namely the design of the questionnaires used to collect data. The study was divided into three phases: in phase 1, data were collected to characterize the participants (in terms of their earlier learning; their proficiency in Portuguese; their professional activity in their country of birth; their professional activity in Portugal; the computing devices they have and use). After collecting these data, the respondents (refugees) with an active profile were identified and invited to participate in the study. In phase 2 type of online social networks used by the respondents with an active profile were identified, as well as the digital competences they assume to have developed), so that in phase 3 we could conceive and carry out training sessions, with the inputs from experts, to develop digital competences. Thus, the main goal of this work is to present the methodology used to build the informal Guide, as well as depict some of the most relevant characteristics of the selected participants.
\end{abstract}

Keywords: Digital Competences; Cognitive Theory of Multimedia Learning; Adult Learners; Online Social Networks; Resettled Refugees

\section{INTRODUCTION}

Online Social Networks (OSN) allows individuals to represent themselves, and administer their own virtual world on personal pages, having a huge popularity in the business context and within socia communication and interaction. Jan (2017) defines OSN as distinctive virtual community sites, such as Facebook, Twitter, YouTube, among others. Indeed, 50 to 70 million active users join Facebook and Twitter each month (Jan 2017). The variety of OSN differs when it comes to functionalities, i.e. tools that enable collaboration, networking, video-sharing; micro-blogging and blogging; and image sharing Different OSN are used to satisfy social and psychological needs of individuals, and its importance and use have also been extended to an educational level (Dahya, 2016; Dahya \& Dryden-Peterson, 2017). Some authors (Cristina, Wolfgand, \& Siqueira, 2016; Lecluijze, De Haan, \& Ünlüsoy, 2015; Mislove, Marcon, Gummadi, Druschel, \& Bhattacharjee, 2007) have identified several issues in the use OSN to promote discussion and interaction, allowing for participants to develop digital skills. It also problematic to evaluate the participant's performance in dealing with OSN, as well as to identify the best way to orient them. Thus, in this work we aim to present the methodology used to build the informal Guide. Based on the literature review, the Cognitive Theory of Multimedia Learning was selected as theoretical and methodological background to create an informal Guide for resettled refugees to develop digital competences, as presented below. 


\section{LITERATURE REVIEW}

This work is part of an ongoing study that aims to investigate the role of OSN to develop digital competences, in order to help resettled refugees in the active job search. In fact, OSN could pose an opportunity for resettled refugees (RR) to development of digital competences, which, as authors have shown, play a vital role in refugee's day-to-day life (Shariati \& Armarego, 2017).

The latest version of Digital Competence Reference Framework of the Joint Research Center DigComp 2.1 was the key reference used for the definition of concept of digital competence (Carretero, Vuorikari, \& Punie, 2017). This framework was tested and verified since its first implementation in 2013 (Janssen et al., 2013) and it has undergone different updates due to its application in different educational contexts, as well as the research carried out (Carretero et al., 2017).

The DigComp 2.1 framework intended to be descriptive and non-prescriptive, and consists of five dimensions, namely: competence areas identified to be part of digital competence (dimension 1); competence descriptors and titles that are pertinent to each area (dimension 2); proficiency levels of each competency (dimension 3); the knowledge skills and attitudes applicable to each competence (dimension 4); and examples of use, on the applicability of the competence to different purposesFor Vuorikari et al. (2016), the DigComp 2.1 framework can be used in education, training, employment, as well as decision and policy support contexts. It can additionally be used as an instrument to orchestrate education and training; respond to issues related to employability, as well as the evaluation and certification of citizens. The dimension 1 of DigComp 2.1 framework is composed of five areas (Information and data literacy; communication and collaboration; digital content creation; safety and problem-solving), which are presented as the areas of the DCD concept, adopted in this analysis model.

On the other hand, job search determines how individuals find job opportunities, and it poses as a prerequisite for prosperous employment (Bao \& Luo, 2016). A job search can be characterized as an objective-oriented activity that begins with the apperception of an employment goal and the effort to reduce the gap between the desired reality and its efficacious reach. According to Fieseler, Meckel, e Muller, 2014, the Internet has changed the way people look for jobs, so it is essential to develop awareness as to the activities that have to be carried out, to avoid "lag behind" when searching for a job. The authors (Fieseler, Meckel, e Muller, 2014) state that OSN present themselves as job search bridges, through the resources available to them, sanctioning access to unique job information, or even spontaneously disseminating their professional curriculum.

To support the development of digital competences through OSN by resettled refugees, , in a scenario of active job search, to the aim is to build an informal Guide, predicated on: i) their interests and active profile, ii) the OSN used by them, iii) their level of digital competences, and iv) the Cognitive Theory of Multimedia Learning (CTML) principles.

According to Mayer (2014a, 2014b), CTML fixates on the cognitive processes involved in learning, such as culling pertinent information, mentally organizing the material into a coherent organization, and integrating it with pertinent prior knowledge activated from long-term memory, and the role of motivation, to engage in the cognitive processes of culling, organizing, and integrating information for meaningful learning. Thus, to identify the prior learning of the resettled refugees, in phase 1 , we characterized the participants, as to education and training; their proficiency level in Portuguese; their professional activity in their country of origin; job search activity in Portugal; computing devices used, etc.. After collecting this information, we characterized each refugee with an active profile as illustrated in table 1.

Table 1. Characteristics of Active Profile Manifestation

\begin{tabular}{|c|c|}
\hline Characteristics & Indicators \\
\hline General information & $\begin{array}{ll}\text { - } & \text { Interacts with people from the host country. } \\
\text { - } & \text { Occupies leisure time with activities of his interest. } \\
\text { - } & \text { Adapts to the lifestyle of the host country. } \\
\text { - } \quad \text { Has as a priority the development of digital skills. } \\
\text { - Has as priority to learn active job search techniques. }\end{array}$ \\
\hline $\begin{array}{l}\text { Language } \\
\text { qualifications }\end{array}$ & $\begin{array}{l}\text { - Understands any type of oral speech in Portuguese. } \\
\text { - Is able to express himself in Portuguese easily. } \\
\text { - Is able to write texts in Portuguese. }\end{array}$ \\
\hline
\end{tabular}

Comentado [A1]: Falta inserir aqui a definição de DC entre aspas. Diretamente copiada do cocumento com referência à página de onde foi retirada 


\begin{tabular}{|l|ll|}
\hline Professional Skills & $:$ & $\begin{array}{l}\text { Has or Had a professional activity. } \\
\text { Enjoys working with others and with people of different } \\
\text { cultures. }\end{array}$ \\
\hline $\begin{array}{l}\text { Education } \\
\text { Training }\end{array}$ & and & $\begin{array}{l}\text { Has attended full basic education. } \\
\text { internet access. }\end{array}$ \\
& $: \begin{array}{l}\text { Has internet access at home and uses it daily. } \\
\text { Has ICT skills. }\end{array}$ \\
\hline
\end{tabular}

The prior learning reveals a critical issue to take into consideration to construct our informal Guide, although refugees are often characterized as victims, in suffering, with no voice, no capacity for action or decision about their own life. They are perceived as individuals who have lost their identity and history, their uniqueness and capacity for political and social action as universal categories. Refugees are not deprived of their identity, bringing in their experience, knowledge and professional skills - useful for the social, economic and cultural development of the host societies (Matos, 2011). For this reason, in the operationalization of the concept of 'active resettled refugee', we considered the Profile Tool for Third Country Nationals, developed by the European Commission, to identify the profile of these refugees with regard to: their heterogeneity; skills, abilities, qualifications, specific needs; opinions; memories and life trajectories (cultural, local and transnational relations (Coelho, 2016). Consequently, the resettled refugees that present the characteristics presented on table 1, were considered in phase 2 of the project, in which the aim was to identify the OSN used by them and their digital competences. Mayer (2014a) also discusses the importance to incorporate motivational features focused on three instructional design goals: less is more (design features that reduce extraneous processing and manage essential processing); more is more (use design features that motivate learners to engage in generative processing); focused more is more (use design features that motivate learners to engage in generative processing, while also providing enough guidance to mitigate excessive extraneous processing). For example, challenging learning situations, providing sufficient time and guidance to attain learning objective (Mayer, 2014a).

In other words, Mayer's CTML presents the conception that we do not interpret multimedia presentations of words, pictures, and audio information in a mutually exclusive way because the elements are collected and organized dynamically to engender a logical construct. Furthermore, Mayer (2014a) underscores the paramount of learning, based upon the testing of a content, to prove the successful knowledge transfer, when new information is integrated with prior knowledge (Ayres, 2015). Therefore, in the next topic, we present the methodological design, to construct our informal Guide.

\section{METHODOLOGY TO DESIGN AN INFORMAL GUIDE}

The research project presently divides into three phases. In phase 1, we collected data to characterize the participants; in phase 2, we collected information as to the type of OSN used by the participants and the digital competences that they assumed to have; and, finally, in phase 3, we and the purpose is to carry out training sessions to support the development of digital competences by active resettled refugees, in a scenario of active job search.

To build this Guide, in phase 1 and 2 of the study, we created two data collection instruments, more precisely, two questionnaires. The first was used to characterize the resettled refugees. With this instrument, it was possible to verify which of the participants indicated by the Portuguese Council for Refugees, showed an active profile, and met the requirements identified in table 1 . These characteristics emerged from the research analysis model, grounded on the goals and research questions of the study, i.e. : How can online social networks be used to develop digital competences of active resettled refugees in a scenario of active job search? From this general question seven specific questions (SQ) emerged, namely: SQ1: How active resettled refugees understand the digital competences?; SQ2: Which activities can be used to develop information and data literacy, in a scenario of active job search, using OSN used by active resettled refugees? ; SQ3: Which activities can be used to develop communication and collaboration competences, in a scenario of active job search, using OSN used by active resettled refugees? ; SQ4: Which activities can be used to develop competences in the area content creation, in a scenario of active job search, using OSN used by active resettled refugees; SQ5: Which activities can be used to develop competences in the security area, in a scenario of active job search, using OSN used by active resettled refugees?; SQ6: Which activities can be used to develop problem-solving competences, in a scenario of active job search, using OSN used by active resettled refugees? The 
concepts and dimensions arising from the research question, which allow for answering the general and specific questions of research are presented in the analysis model put forth in table 2.

Table 2. Data analysis model regarding the development of digital competences

\begin{tabular}{|l|c|c|c|c|c|c|c|}
\hline Competence area & GQ & SQ1 & SP2 & SQ3 & SQ4 & SQ5 & SQ6 \\
\hline CA1 - Information and data literacy & $\mathbf{X}$ & $\mathbf{X}$ & $\mathbf{X}$ & & & \\
\hline CA2 - Communication and collaboration & $\mathbf{X}$ & & & $\mathbf{X}$ & \\
\hline CA3 - Digital content creation & $\mathbf{X}$ & & & & $\mathbf{X}$ & \\
\hline CA4 - Security & $\mathbf{X}$ & & & & & $\mathbf{X}$ \\
\hline CA5 - Problem-solving & $\mathbf{X}$ & & & & & \\
\hline
\end{tabular}

\subsection{The questionnaires - structure and target audience}

The first questionnaire included an initial part that aimed at a general characterization of the respondents. It divided into four different groups of questions. The first group encompassed questions to collect data regarding the participants' personal details (gender, age, nationality, legal status, academic qualifications, ICT skills, etc.), information about their experiences and difficulties in Portugal, and their prospects to the future. The second group focused on the participant's native language, and use of the Portuguese language (as to the use of the four skills: reading, listening, writing and reading). In the third group, the questions concerned their professional skills, developed in their country of birth and in Portugal.

The second questionnaire was structured in four groups. The first group concerned only the identification of the respondent, to cross-reference the information given in the first questionnaire. The second group aimed to identify the OSN used by refugees in their daily lives, as well as the OSN they would like to use in the future. The third group regarded their participation in OSN, namely the types of interaction and communication that they establish. Finally, the fourth group refers to the digital competences that they assume to have developed. After constructing both questionnaires (Phase 1 and Phase 2), they were tested and validated, to confirm whether the group categories and the questions formulated, were clear for the participants.

In what concerns the target, in Phase 1, the questionnaire was answered by resettled refugees and beneficiaries of international protection, belonging to the Portuguese Council for Refugees. There was a total of 13 respondents and after analysing general identification data, we concluded that only 11 were refugees with an active profile, i.e. that met the requisites described in table 1 . These 11 participants were selected to answer the questionnaire of Phase 2 . The questionnaires were answered in person, in December 2017, at the Portuguese Refugee Council.

The analysis of the gathered data will be used to build an interview guide addressing experts in the competence areas considered and some of the results are presented below.

\section{RESULTS AND ANALYSIS}

In this section, we present the results and a first analysis of the data collected in the first and second questionnaire, i.e. the characterization of the active resettled refugees, of the OSN used by the participants and of the digital competences that they assume to have developed.

\subsection{Profile of the participants}

As to the 13 respondents of the questionnaire in phase 1, 5 were female and 8 were male, aged from 20 to 56 years old, being the average age 40 years old. In what concerns the participants' origin, they were from Angola $(n=2)$; Eritrea $(n=4)$; Guinea Conakry $(n=2)$; Democratic Republic of Congo $(n=3)$; Togo $(n=1)$; Liberia $(n=1)$. The languages spoken by the respondents were: Persian $(n=1)$; French $(n=4)$; 
Tigrinya $(n=2)$; English $(n=1)$; Lingala $(n=3)$; Portuguese $(n=2)$; and Saho $(n=1)$. Finally, regarding professional opportunities, most of the respondents claimed that it is hard (or very hard) to work in their professional area $(n=7)$; nonetheless, they consider that is relatively easy to adjust to the Portuguese culture $(\mathrm{n}=8)$.

Still regarding data collected in the first questionnaire (Phase 1), and considering language skills, 11 out of the 13 respondents (85\%) refers that they sometimes, often, or always, understand written and spoken Portuguese. Besides, concerning the professional experience of the participants in their country of birth, the jobs identified were: mechanic; librarian; factory worker (marble and tile); accountant; kitchen assistant; seamstress; agency operator; cash operator; receptionist; secretary; barmaid in a pastry shop; joiner; pharmacist technician, and client support. In the host country (Portugal), refugees worked in the areas such: bakery, pastry; customer service; translation; security; cleaning; call centre; construction (renovation /remodelling); and store operator. All refugees assume having had collaborative work style along with work management skills. The number of years of professional experience of resettled refugees in the origin country (see Fig.1) ranges from no work experience to 30 years of professional experience. In the case of two participants (RR8 and RR10), although they did not have work experience in the country of origin, they assumed to have already worked in the host country, three and thirteen years (respectively).

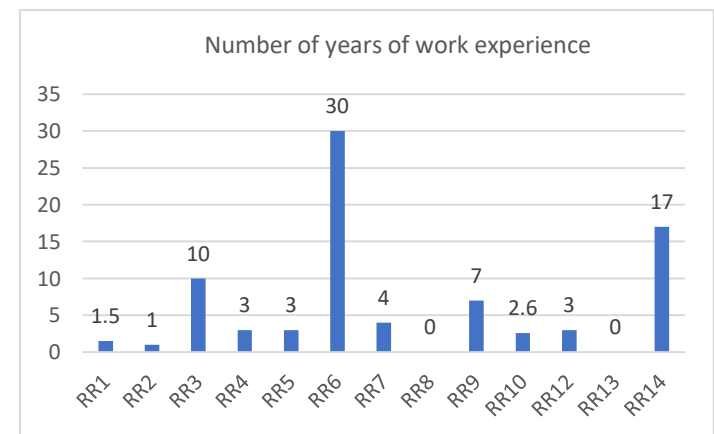

Figure 1. Work experience of resettled refugees in the origin country (in years).

From the 13 participants, 2 assume to have completed basic education; 9 have completed secondary education; 1 higher education, and 1 vocational and secondary education in the country of origin Nevertheless, only 4 respondents did not attend the formal schooling in the host country. Besides, 1 participant refers not having put yet together the necessary documentation to ask for academic recognition in the host country. As far as proficiency in Portuguese is concerned, 11 of the respondents $(85 \%)$ state that they have tried to learn Portuguese, and $8(62 \%)$ have sought training in digital competences. Regarding ICT literacy, $69 \%(n=9)$ of the respondents mention that they have developed these skills autonomously; $38 \%(n=5)$ learned with a teacher in a training course; $38 \%(n=5)$ learned with children and friends; $31 \%(n=4)$ learned at school; $31 \%(n=4)$ learned at work; and finally. The majority of the participants $(n=12 ; 92 \%)$ affirms to have access to the internet through a Wi-Fi network, and uses it every day $(n=11 ; 85 \%)$ in a smartphone.

\subsection{The use of OSN and development of digital competences}

After analyzing the characteristics of the resettled refugees that participate in Phase 1 of this study, those who achieved the requisites defined in table 1 were selected to participate in Phase 2 . To those, we applied the second questionnaire, to identify which OSN they used, and which digital competences they assume to have developed.

When asked which OSN they used more often, respondents $(n=11 ; 100 \%)$ selected the following: YouTube $(n=10 ; 91 \%)$; Facebook $(n=9 ; 82 \%)$; Google+ $(n=8 ; 73 \%)$; WhatsApp $(n=7 ; 64 \%)$; Viber, IMO, Messenger ( $n=3 ; 27 \%)$; Live You Tube $(n=3 ; 27 \%)$; Twitter $(n=2 ; 18 \%)$; Linkedln $(n=1 ; 9 \%)$. Moreover, when asked which OSN they would like to use in future, the answers were the following: Instagram ( $n=9$; $82 \%)$; Linkedln $(n=8 ; 73 \%) ;$ Twitter $(n=7 ; 64 \%)$; Tumblr $(n=6 ; 55 \%)$; Pinterest $(n=6 ; 55 \%)$; Vimeo $(n=6$; $55 \%)$; Live YouTube $(n=5 ; 45 \%)$; SlideShare $(n=4 ; 36 \%)$; WhatsApp $(n=1 ; 9 \%)$; Tango $(n=1 ; 9 \%)$. 
Concerning OSN use, respondents usually use them to interact with their family and friends, share information and content (related to health and work choices, and other valuable information, history and the development of the world, nutrition issues, and information about the current economic situation of their country, and other countries). YouTube and WhatsApp are tools used to keep in touch with the world's news, and Google is used to search for and share information and documents with other resettled refugees. Respondents also see advantages in the use OSN as to taking part in Portuguese society. Some of them refer the use OSN to look for a job and others use them to listen to music. The most important OSN for $73 \%(n=8)$ of the respondents are Facebook; Google and YouTube; LinkedIn; WhatsApp; Viber; IMO, Messenger; Twitter and Google +, and they do not find it difficult to use any of these OSN. In table 3 we present the most important OSN for each participant.

Table 3. OSN more important for the ARR

\begin{tabular}{|l|l|}
\hline ID of ARR & OSN more important for the ARR \\
\hline ARR1 & Facebook \\
\hline ARR2 & [none] \\
\hline ARR3 & Facebook. \\
\hline ARR4 & Google, YouTube. \\
\hline ARR5 & Google, YouTube. \\
\hline ARR6 & Facebook, Google+; Linkedln, WhatsApp; Viber. \\
\hline ARR7 & Imo, Messenger. \\
\hline ARR8 & Facebook, WhatsApp, YouTube; Messenger. \\
\hline ARR9 & Twitter, Google+, Linkedln \\
\hline ARR10 & Facebook, YouTube e Google. \\
\hline ARR11 & Facebook, YouTube; Twitter; Google+; WhatsApp. \\
\hline
\end{tabular}

The characterize the digital competences that participants (active resettled refugees) assume to have developed, a measuring scale was developed, based on DigComp 2.1 levels. Therefore, the scale has the following levels: I don't know how to use digital technology (level 0); I use digital technology always with the support of someone (level 1); I use digital technology with some support when needed (level 2); I use digital technology autonomously (level 3); I use digital technology independently and according to my needs (level 4) ; I use digital technology independently and I can teach others (level 5); I use digital technology and can teach others, adapting to them in a complex context (level 6); I use digital technology and work actively to develop my competences, guide others and put forth new ideas (level 7 and 8).

For each of the competence areas mentioned above (information and data literacy; communication and collaboration; security; digital content creation and problem-solving), the participants mentioned that they did not know how to use the digital technology (level 0), or, could only use it with the help of someone (level 1). One respondent mentioned that he could use digital technology independently and could teach others (level 5). To sum up, we conclude that most of the respondents position themselves in a very low-level of digital competences (level 0 , sometimes 1 , or 2 ), and others show a medium level (4, sometimes 5). Taking this into account, the activities that are being designed to develop with these resettled refugees are divided into two groups: group 1 for active resettled refugees that shown a lowlevel and another group 2 for those with more advanced digital coompetences. 


\section{CONCLUSIONS}

Phase 1 and 2 of this study unveiled that not every resettled refugee has an active profile and, consequently, only 11 individuals were considered to continue the study. Moreover, these 11 active resettled refugees are interested and motivated to take part in the working sessions to further develop their digital competences, using the informal Guide. The aim is to develop the activities using the OSN that participants considered most important, as well as those that they do not use yet, but would like to use in the future. In addition to these OSN, we will also consider those that allow for creating digital content, such as Canvas (https://www.canva.com/). Given the diversity of professional areas, the professional focus will be transversal.

Some respondents found the four competences areas important; nevertheless, most of them position themselves at level 0 or 1 and others assume that they are on level 3 or 5 - but never higher. For this reason, participants will be divided into two groups, the first group for participants with a low-level digital competences (level 0 to 2), and a second group with an average-level digital competences (level 4 to 5 ). For the former, the working sessions will focus the development of level 3,4 and 5 of digital competences, and for the latter, the working sessions will emphasize the level 6 and 7 .

Summing up, considering the literature review and the gathered data, the development of the Guide should have an introductory module, where common concepts and the utilities of the OSN are set up, followed by activities in the different competence areas, i.e. information and data literacy area, communication and collaboration, digital content creation, and problem-solving. For each module of the informal Guide, the learning objectives of the activities will also be presented. Although the DigComp 2.1 Carretero et al., 2017) puts forth some examples of activities, it does not encompass all the specific areas that will be included in the guide. In other words, the design of this informal Guide will also take into consideration cognitive processes involved in learning, such as selecting pertinent information and integrating new knowledge with pertinent prior knowledge activated from long-term memory, to engage in the cognitive processes of selecting, organizing, and integrating information for meaningful learning.

\section{ACKNOWLEDGEMENTS}

Once more, I greatly appreciate the collaboration and support of the Portuguese Council for Refugees, to allow us to carry out the phase I and II of the study in their organization.

Furthermore, this work is financially supported by National Funds through FCT - Fundação para a Ciência e a Tecnologia under the project UID/CED/00194/2013.

\section{REFERENCES}

Ayres, P. (2015). State-of-the-Art Research into Multimedia Learning: A Commentary on Mayer's Handbook of Multimedia Learning, 636(June), 631-636.

Bao, Z., \& Luo, P. (2016). How College Students' Job Search Self-efficacy And Clarity Affect Job Search Activities. Social Behavior and Personality: An International Journal, 44(3), 39-51. https://doi.org/10.2224/sbp.2015.43.1.39

Batista, J. C. L. (2011). O Uso das Tecnologias da Comunicação no Ensino Superior. Universidade de Aveiro. Retrieved from https://ria.ua.pt/bitstream/10773/8788/1/6227.pdf

Carretero, S., Vuorikari, R., \& Punie, Y. (2017). The Digital Competence Framework for Citizens With eight proficiency levels and examples of use. Luxembourg. https://doi.org/10.2760/38842

Coelho, J. M. B. L. (2016). Mulheres Refugiadas em. ISCTE - Instituto Universitário de Lisboa. Retrieved from https://repositorio.iscte-iul.pt/bitstream/10071/11465/1/DissFINAL Joana LUCAS COELHO.pdf

Cristina, V., Wolfgand, S., \& Siqueira, M. (2016). Analysing Students Interactions Through Social Presence And Social Network Metrics. In International Conferences ITS, ICEduTech and STE 2016 (pp. 123-130). Rio de Janeiro.

Dahya, N. (2016). Education in Conflict and Crisis: How Can Technology Make a Difference? A Landscape Review (Sector Pro). Deutsche Gesellschalt für Internationale Zusammenarbeit (GIZ) $\mathrm{GmbH}$. 
http://www.wvi.org/sites/default/files/20160303_Landscape_Review_ICT4E_in_Conflict_and_Cri sis.pdf

Dahya, N., \& Dryden-Peterson, S. (2017). Tracing pathways to higher education for refugees: the role of virtual support networks and mobile phones for women in refugee camps. Comparative Education, 53(2), 284-301. https://doi.org/10.1080/03050068.2016.1259877

Fieseler, C., Meckel, M., \& Muller, S. (2014). With a little help from my peers. the supportive role of online contacts for the unemployed. Computers in Human Behavior, 41, 164-176. https://doi.org/10.1016/j.chb.2014.09.017

Jan, M. T. (2017). Why Do You Adopt Social Networking Sites? Investigating the Driving Factors through Structural Equation Modelling. Interactive Technology and Smart Education, 14(4), 266 278. https://doi.org/https://doi.org/10.1108/ITSE-08-2016-0024

Lecluijze, S. E., De Haan, M., \& Ünlüsoy, A. (2015). What Online Networks Offer: Online Network Compositions and Online Learning Experiences of Three Ethnic Groups. International Journal of Higher Education, 4(3), 68-81. https://doi.org/10.5430/ijhe.v4n3p68

Matos, T. N. da C. C. (2011). A Inserção dos Refugiados Reinstalados no Mercado de Trabalho - Uma Etapa num processo de integração? Universidade de Lisboa. Retrieved from http://refugiados.net/1cpr/www/reinstalacao/tese_de_mestrado_tito_matos_2011_integracao_pro fissional_refugiados_reinstalados.pdf

Mayer, R. E. (2014a). Incorporating motivation into multimedia learning q. Learning and Instruction, 29, 171-173. https://doi.org/10.1016/j.learninstruc.2013.04.003

Mayer, R. E. (2014b). The Cambridge Handbook of Multimedia Learning. (R. E. Mayer, Ed.) (2nd ed.).

Mislove, A., Marcon, M., Gummadi, K. P., Druschel, P., \& Bhattacharjee, B. (2007). Measurement and analysis of online social networks. In Proceedings of the 7th ACM SIGCOMM conference on Internet measurement - IMC '07 (p. 29). https://doi.org/10.1145/1298306.1298311

Santinho, M. C. (2011). Refugiados E Requerentes De Asilo Em Portugal: Contornos Políticos No Campo Da Saúde. Iscte-Instituto Universitário de Lisboa. Instituto Universitário de Lisboa. Retrieved from https://repositorio.iscte-iul.pt/bitstream/10071/3512/3/TESE FINAL_14Junho2011.pdf

Shariati, S., \& Armarego, J. (2017). The Impact of E-Skils on the Settlement of Iranian Refugees in Australia, 13, 59-77.

Trindade, A., Balula, A., \& Miranda, G. (2017). The use of Online social networks, for the acquisition and development of digital competences. In INTED2017 (Ed.), Proceedings of INTED2017 Conference (pp. 6133-6139). Valência.

Turton, D. (2003). Conceptualising Forced Migration. Oxford Refugee Studies Centre, Working Paper Series, 12(12), 1-17. https://doi.org/10.1016/S0140-6736(02)75763-2

Vuorikari, R., Punie, Y., Carretero, S., \& Van Den Brande, L. (2016). DigComp 2.0: The Digital Competence Framework for Citizens. Update Phase 1: The Conceptual Reference Model (Luxembourg). Luxembourg. https://doi.org/10.2791/11517 